\title{
Further studies on immunomodulatory effects of exopolysaccharide isolated from Lactobacillus rhamnosus KL37C
}

\author{
MARTA CISZEK-LENDA ${ }^{l}$, BERNADETA NOWAK ${ }^{1}$, MALGORZATA SROTTEK ${ }^{l}$, MARIA WALCZEWSKA ${ }^{l}$, \\ SABINA GORSKA-FRACZEK ${ }^{2}$, ANDRZEJ GAMIAN ${ }^{2}$, JANUSZ MARCINKIEWICZ ${ }^{\prime}$
}

${ }^{1}$ Chair of Immunology, Jagiellonian University, Medical College, Krakow, Poland

${ }^{2}$ Laboratory of Medical Microbiology, Ludwik Hirszfeld Institute of Immunology and Experimental Therapy, Polish Academy of Sciences, Wroclaw, Poland

\begin{abstract}
Lactobacilli, bacteria of human microbiome and major probiotic bacteria, show immunoregulatory properties. The immunomodulatory effect can be achieved not only by whole bacteria but also by cellwall components such as peptidoglycan and lipoteichoic acid (LTA). Other, biological active bacterial products are exopolysaccharides (EPS), major components of the lactobacilli biofilm. The aim of this study was to examine immunostimulatory potential of highly purified EPS derived from L. rhamnosus $K L 37\left(E P S_{37}\right)$. We have examined the effect of $E P S_{37}$ on some selected biological functions of major inflammatory cells (neutrophils, macrophages, dendritic cells) in vitro, and on OVA-specific humoral response in mice. We have shown weak antioxidant properties of $E P S_{37}$. It decreased the reactive oxygen species (ROS) production in neutrophils stimulated with zymosan, but had no effect on phagocytosis of dextran by macrophages. Interestingly, in contrast to LTA, pure EPS 37 did not stimulate cytokine production by $M \Phi$. Moreover, $E P S_{37}$ did not induce synthesis of prostaglandin $E_{2}\left(P G E_{2}\right)$ and did not affect the expression of COX-2 protein in $M \Phi$, while it slightly induced the production of IL-12p40 and of IL-6 but not IL-10, in dendritic cells. On the other hand, we have found that EPS 37 diminished the production of OVA-specific IgG antibodies. Moreover, EPS 37 inhibited the adjuvant effect of LPS. Therefore, our present results confirm the suppressor effect of $E P S_{37}$ on antigen-specific humoral response in mice. These data extend our knowledge about the role of EPS in interaction between bacteria and the immune system. However, further studies are necessary to explain its role as a major component of biofilm matrix.
\end{abstract}

Key words: biofilm, cytokines, exopolysaccharides, Lactobacillus rhamnosus, lipoteichoic acid, macrophages, dendritic cells, probiotics.

(Centr Eur J Immunol 2013; 38 (3): 289-298)

\section{Introduction}

Recently, an increasing number of studies have suggested that the immunoregulatory effect of probiotic bacteria can be achieved not only by using live or dead bacteria, but also by using components of the bacterial cell wall or their secretory products such as exopolysaccharides (EPS) excreted into the environment during growth of bacteria [1, 2]. Most lactic acid bacteria are capable of synthesizing and secreting EPS. Lactobacillus, Streptococcus and Lactococcus prevail among these genera but also it can be produced by some strains of Bifidobacterium [3-6]. Over 50 different exopolysaccharides derived from lactic acid bacteria have been described, and more than 30 of these bacteria belong to Lactobacillus [7].

EPSs are linear macromolecular carbohydrate biopolymers which potentially express biological activity [8]. Lactobacillus bacteria can both secrete EPS to the environment and synthesize its cell wall-bound type. EPS, which is the main component of biofilm, facilitates adhesion of bacteria to intestinal epithelium, enables bacterial cells to sur-

Correspondence: Prof. Janusz Marcinkiewicz, Chair of Immunology, Jagiellonian University Medical College, Czysta 18, 31-121 Krakow, Poland, e-mail: mmmarcin@cm-uj.Krakow.pl 
vive in bile salts [9] and prevents infection of bacteria by the bacteriophage [10]. Genes encoding enzymes and proteins required for EPS synthesis have been discovered and described [11]. However, involvement of EPS in an interaction between Lactobacillus bacteria and MALT system is not fully understood. It is not known either whether a receptor for EPS exists.

In our previous study we have shown immunomodulating properties of crude EPS isolated form Lactobacillus rhamnosus KL37C [12]. We have compared the effect of EPS on production of inflammatory mediators by mouse peritoneal macrophages with the effect of lipopolysaccharide (LPS). EPS could effectively stimulate production of cytokines by macrophages, especially tumor necrosis factor $\alpha$ (TNF- $\alpha$ ), interleukin 6 (IL-6) and IL-12. However, its stimulatory potential was significantly lower than that of LPS. Furthermore, our data demonstrated that exposure of macrophages to LPS induced a state of hyporesponsiveness, as indicated by a reduced production of TNF- $\alpha$ after restimulation with either LPS or EPS ('cross-tolerance'). Our results also indicated that inhibitors of both ERK and p38 MAPKs inhibit production of TNF- $\alpha$ induced by LPS or EPS. Elsewhere, we have shown that Lactobacillus rhamnosus exopolysaccharide ameliorates arthritis induced by a systemic injection of collagen and lipopolysaccharide in DBA/1 mice [13]. However, further studies with highly purified EPS are necessary to find out whether EPS can be clinically useful as an immunomodulatory agent.

In the present study we have focused on analyzing in vitro immunoregulatory properties of a highly purified exopolysaccharide from L. rhamnosus $\mathrm{KL} 37 \mathrm{C}\left(\mathrm{EPS}_{37}\right)$. The immunostimulatory potential of $\mathrm{EPS}_{37}$ was compared with that of lipoteichoic acid (LTA) isolated from the same bacteria and with LPS from Escherichia coli. We have examined the effect of EPS on some selected biological functions of major inflammatory cells, namely, neutrophils, macrophages and dendritic cells.

\section{Material and methods}

\section{Mice}

Inbred CBA/J mice and Balb/c mice (8-12 weeks of age, 18-22 g) were maintained in the Animal Breeding Unit, Chair of Immunology, Jagiellonian University Medical College, Krakow. All mice were housed in the laboratory room with water and standard diet ad libitum. The authors were granted permission by the Local Ethics Committee to use mice in this study.

\section{$\mathrm{EPS}_{37}$ isolation}

Exopolysaccharide was obtained from L. rhamnosus KL37C strain as described before [14]. The strain was isolated from feces of human newborns and then stored at $-70^{\circ} \mathrm{C}$ in MRS broth supplemented with $10 \%$ glycerol. Bac- teria were cultivated in supplemented MRS liquid broth (Oxoid, UK) under anaerobic conditions at $37^{\circ} \mathrm{C}$ for $48 \mathrm{~h}$. Cells were harvested by centrifugation at $7300 \mathrm{~g}\left(4^{\circ} \mathrm{C}, 30\right.$ min) and washed twice with PBS. Freeze-dried bacterial mass was extracted with $10 \%$ TCA $\left(25^{\circ} \mathrm{C}, 2 \mathrm{~h}\right)$ and then centrifuged at $14500 \mathrm{~g}$ for $20 \mathrm{~min}$. The pellet was discarded and $\mathrm{EPS}_{37}$ from the supernatant was precipitated with 5 volumes of cold $96 \%$ ethanol $\left(4^{\circ} \mathrm{C}, 16 \mathrm{~h}\right)$ and collected by centrifugation at $23500 \mathrm{~g}\left(4^{\circ} \mathrm{C}, 50 \mathrm{~min}\right)$. The pellet was suspended in water, dialyzed for $48 \mathrm{~h}$ against water and then lyophilized.

\section{EPS $_{37}$ purification}

Freeze-dried preparation of crude $\mathrm{EPS}_{37}$ was dissolved in buffer $(50 \mathrm{mM}$ Tris- $\mathrm{HCl} \mathrm{pH} 7.5,10 \mathrm{mM} \mathrm{MgCl} 2)$ and treated with DNase and RNase $\left(37^{\circ} \mathrm{C}, 6 \mathrm{~h}\right)$ and with protease from Streptomyces griseus $\left(37^{\circ} \mathrm{C}, 16 \mathrm{~h}\right)$ (both SigmaAldrich, Germany), then dialyzed against water at $4^{\circ} \mathrm{C}$ for $24 \mathrm{~h}$. Resuspended polysaccharide was purified by ionexchange chromatography on $1.6 \times 20 \mathrm{~cm}$ DEAE-Sephadex A-25 column (Pharmacia Fine Chemicals, Sweden). EPS 37 was eluted with $20 \mathrm{mM}$ Tris buffer $\mathrm{pH}$ 8.2. Fractions containing $\mathrm{EPS}_{37}$ were pooled, desalted by dialysis against water at $4^{\circ} \mathrm{C}$ for $24 \mathrm{~h}$ and lyophilized.

\section{LTA isolation}

Defrosted aliquot of bacteria was mixed with equal volume of $n$-butanol (Merck, Germany) under stirring for 30 min at RT. After centrifugation at $13000 \mathrm{~g}$ for $20 \mathrm{~min}$, the aquatic phase was collected and dialyzed against distilled water, lyophilized, resuspended with chromatography start buffer (15\% n-propanol in $0.1 \mathrm{M}$ ammonium acetate, $\mathrm{pH}$ 4.7) and centrifuged at $45000 \mathrm{~g}$ for $15 \mathrm{~min}$. The supernatant was subjected to hydrophobic interaction chromatography on $1.6 \times 40 \mathrm{~cm}$ octyl-Sepharose CL-4B column (Pharmacia Fine Chemicals, Sweden). Unbound material was washed out with start buffer. Afterwards, bound materials were eluted with $35 \%$-propanol in $0.1 \mathrm{M}$ ammonium acetate buffer ( $\mathrm{pH}$ 4.7). Column fractions containing LTA were pooled and dialyzed against distilled water.

\section{Macrophages}

Peritoneal mouse $(\mathrm{CBA} / \mathrm{J})$ macrophages $(\mathrm{M} \Phi)$ were induced by an intraperitoneal injection of $2.0 \mathrm{ml}$ of thioglycolate (Sigma, USA). Cells were collected $72 \mathrm{~h}$ later by washing out the peritoneal cavity with $5 \mathrm{ml}$ of DPBS containing $5 \mathrm{U}$ heparin/ml (Polfa, Poland). Cells were centrifuged and red blood cells were lysed. Osmolarity was restored by addition of PBS. At least three mice were used as donors of peritoneal macrophages for each experiment.

\section{Dendritic cells}

Bone marrow derived dendritic cells (DC) were cultured from Balb/c mice. Briefly, bone marrow cells were flushed 
out from femurs and grown at starting density of $2 \times 10^{6}$ cells/ml of IMDM (Cytogen, Germany). The medium was supplemented with HEPES (24 g/l), $50 \mathrm{nM}$ of 2-mercaptoethanol (both Sigma-Aldrich, Germany), 10\% FBS (PAA, USA), gentamicin (50 mg/ml, Krka, Slovenia) and $3 \mathrm{ng} / \mathrm{ml}$ GM-CSF (Invitrogen, USA). After 3 days, the medium containing most of non-adherent cells, was removed and replaced with the fresh one. None adherent DCs, released spontaneously from proliferating cell clusters, were recovered at $7^{\text {th }}$ day of culture. Prepared cells were suspended in PBS containing $0.05 \%$ FBS and $2 \mathrm{mM}$ EDTA and purified with Magnetic Advanced Cell Sorting system (MACS, Miltenyi Biotec, Germany). Firstly, cells were incubated on ice for 40 min with anti-CD11c antibodies. Then, cells were washed in PBS and passed through a column with iron wool placed in the magnetic field. First collected fractions of cells were $\mathrm{CD} 11 \mathrm{c}$ negative. After removing the column from the magnetic field, CD11c-positive cells were collected. Thus, purified DC were suspended in the culture medium IMDM and used for further experiments.

\section{Reactive oxygen species generation: luminol-dependent and lucigenine-dependent chemiluminescence assay}

The effect of $\mathrm{EPS}_{37}$ on induction production of reactive oxygen species (ROS) by neutrophils was evaluated in vitro using luminol-dependent chemiluminescence or lucigenine-dependent chemiluminescence. Chemiluminescence was counted at $37^{\circ} \mathrm{C}$ in temperature-stabilized luminometer Lucy 1 (Anthos, Austria). Briefly, 18-hour peritoneal cells induced by thioglycolate $\left(5 \times 10^{5} /\right.$ well $)$, were preincubated with tested agents in Hank's balanced salt solution $\left(60 \mathrm{~min}\right.$ at $37^{\circ} \mathrm{C}$ in an atmosphere of $5 \% \mathrm{CO}_{2}$ ) on a 96-well flat-bottom black plate (Nunc, Denmark). Then, the cells were mixed with luminol $(0.8 \mathrm{mg} / \mathrm{ml})$ or lucigenine $(0.25$ $\mathrm{mM})$ in $1: 1$ volume ratio (both Sigma-Aldrich, Germany) and incubated at $37^{\circ} \mathrm{C}$ for another $30 \mathrm{~min}$. After incubation, the cells were quickly stimulated with yeast zymosan (200 $\mu \mathrm{g} / \mathrm{ml}$, Sigma-Aldrich, Germany) and photon emission over 75 min with 3-min intervals was measured. Results are expressed as relative light units (RLU) where photons were counted every 5 seconds.

\section{HOCl-specific UV absorption spectra measurement}

$\mathrm{HOCl}$ concentration was determined before each reaction by UV absorption spectra $(\lambda=200$ to $400 \mathrm{~nm})$ measured at $292 \mathrm{~nm}$ using extinction coefficient factor 350 $\mathrm{M}^{-1} \mathrm{~cm}^{-1}$. $\mathrm{HOCl}$ and $\mathrm{EPS}_{37}$ were mixed in concentration $1 \mathrm{mM} \mathrm{HOCl}$ and $100 \mu \mathrm{g} / \mathrm{ml} \mathrm{EPS}_{37}$ and incubated for $5 \mathrm{~min}$ in RT. Each reaction of $\mathrm{HOCl}$ with $\mathrm{EPS}_{37}$ was monitored by UV absorption spectra $(\lambda=200$ to $400 \mathrm{~nm})$ to estimate the influence of $\mathrm{EPS}_{37}$ on UV spectra of $\mathrm{HOCl}$.

\section{Macrophage culture and treatment}

M $\Phi$ were cultured in 24-well flat-bottom cell culture plates $(5 \times 105 /$ well $)$ IMDM (Cytogen, Germany) supplemented with $5 \% \mathrm{FBS}$, and gentamicin at $37^{\circ} \mathrm{C}$ in atmosphere of $5 \% \mathrm{CO}_{2}$. After $1 \mathrm{~h}$, non-adherent cells were removed, whereas the adherent cells were stimulated with indicated concentrations of $\mathrm{EPS}_{37}$, LTA and LPS ( $E$. coli 001:B4; Sigma-Aldrich, Germany) After 24 h, culture supernatants were collected and frozen at $-80^{\circ} \mathrm{C}$ until used. All groups were investigated in duplicates.

\section{Dendritic cell culture and treatment}

Dendritic cell prepared as described above, were cultured on 96-well plates in IMDM supplemented with 5\% FBS, HEPES and gentamicin at $37^{\circ} \mathrm{C}$ in atmosphere of $5 \%$ $\mathrm{CO}_{2}$. Cells were stimulated with selected concentrations of examined bacterial structures, and after $24 \mathrm{~h}$ supernatants were collected and level of cytokines IL-6, IL-10 and IL-12p40 was estimated.

\section{Cytokines determination}

The concentration of cytokines in supernatants was determined using the ELISA method with some modifications, as described before [12]. 96-well plates (Costar, USA) were coated with antibody against the selected cytokine (TNF- $\alpha$, IL-2, IL-6 and IL-12p40 - Bioscience, USA) and incubated for $24 \mathrm{~h}$ at $4{ }^{\circ} \mathrm{C}$. After blocking the plate with a solution of $3 \%$ skimmed milk $(2 \mathrm{~h})$, tested samples and standards for each of the cytokines were applied. After further $24 \mathrm{~h}$ of incubation at $4^{\circ} \mathrm{C}$, biotinylated antibodies against the selected cytokine were added for $1 \mathrm{~h}$. The ELISA was developed using horseradish peroxidase conjugated with streptavidin (Vector, USA) followed by o-phenylenediamine and $\mathrm{H}_{2} \mathrm{O}_{2}$ (both Sigma-Aldrich, Germany). After $30 \mathrm{~min}$, reaction was stopped by addition of $3 \mathrm{M} \mathrm{H}_{2} \mathrm{SO}_{4}$. The optical density of each sample was measured at $492 \mathrm{~nm}$ in microplate reader PowerWavec (Bio-Tek Instruments, USA). $0.05 \%$ Tween20 in phosphate buffer was used as a washing solution. Exception to the above procedure was the measurement of IL-10, which was performed according to the manufacturer's instructions (BD Biosciences, USA).

\section{Phagocytosis}

To evaluate the effect of EPS on phagocytosis of dextran by macrophages, cells were resuspended in $1 \%$ FBS in PBS and then incubated with $\mathrm{EPS}_{37}$ or LPS and RITC-dextran (Sigma-Aldrich, Germany) for $30 \mathrm{~min}$ at $37^{\circ} \mathrm{C}$. The reaction was stopped by addition of cold $1 \%$ FBS in PBS. Cells were washed three times using the same buffer, and then macrophages were prepared for analysis by flow cytometry. Cells were stained with allophycocyanin-conjugated anti-mouse F4/80 monoclonal antibody (eBioscience, USA). Nonspecific binding was blocked using monoclonal 2.4G2 antibody (BD Pharmingen, USA). Cells 
were incubated with antibodies for $40 \mathrm{~min}$, at $4{ }^{\circ} \mathrm{C}$ in the dark, then washed twice with $1 \%$ FBS in PBS and suspended for analysis in the same buffer. To exclude dead cells, propidium iodide was added just before analysis (Sigma-Aldrich, Germany). Cells were analyzed using FACSCalibur flow cytometer (Beckton Dickinson, USA) and CellQuest Pro software (Beckton Dickinson, USA).

\section{$\mathrm{PGE}_{2}$ determination}

$\mathrm{PGE}_{2}$ concentration in supernatants was determined by Prostaglandin $\mathrm{E}_{2}$ Monoclonal EIA kit (AssayDesigns, USA) according to the manufacturer's instructions.

\section{Western blot analysis: evaluation of COX-2 expression}

The level of induction of COX-2 protein was determined by the Western blot technique. МФ were lysed in lysis buffer containing mixture of protease inhibitors (Sigma-Aldrich, Germany). The total protein concentration in resulting lysates was determined using a bicinchoninic acid protein assay kit (Sigma-Aldrich, Germany). Samples containing equal amounts of protein (14 mg) were suspended in loading buffer (reagents Sigma, USA), in a $2: 1$ ratio and denatured for $4 \mathrm{~min}$ at $100^{\circ} \mathrm{C}$. Samples were applied to polyacrylamide gel with $10 \%$ SDS and were separated electrophoretically in the Laemmli system using Mighty Small II apparatus (Amersham Biosciences, USA) [15]. Separated proteins were transferred to the nitrocellulose membrane (Bio-Rad, USA) using Hoefer TE22 transfer equipment (Amersham Biosciences, USA). After overnight incubation with protein blocking solution at $4{ }^{\circ} \mathrm{C}$ (3\% skimmed milk), membranes were incubated for $2 \mathrm{~h}$ at RT with rabbit polyclonal anti-COX-2 antibodies (Cayman, USA) and mouse monoclonal anti- $\beta$-actin antibodies (Sigma-Aldrich, Germany). Then, membranes were incubated for $2 \mathrm{~h}$ with secondary antibodies, anti-rabbit IgG (Sigma-Aldrich, Germany) and goat IgG conjugated with phosphatase alkaline (Sigma-Aldrich, Germany) at RT. The bands were detected with phosphatase alkaline substrate BCIP/NBT (Sigma, USA). Protein bands were scanned and analyzed using freeware Scion Image for Windows (Scion, USA). Results are presented as a ratio of optical density of protein to $\beta$-actin, which is constitutively expressed in cells.

\section{Mice immunization with OVA}

Mice were immunized intraperitoneally with OVA ( $200 \mu \mathrm{g} / \mathrm{mouse})$ in the presence of LPS ( $1 \mu \mathrm{g} / \mathrm{mouse}$; both Sigma-Aldrich, Germany), or/and of $\mathrm{EPS}_{37}(50 \mu \mathrm{g} / \mathrm{mouse})$ or/and of LTA ( $50 \mu \mathrm{g} / \mathrm{mouse}$ ) twice, on days 0 and 14 . Seven days after the second immunization mice were bled and serum was processed further.

\section{Measurement of serum OVA-specific antibody titers}

The level of antibodies specific to OVA in mouse serum was determined using the ELISA test as described before
[13]. Briefly, plates were coated with OVA $(5 \mu \mathrm{g} / \mathrm{ml})$ overnight. Serial dilutions of mouse serum in PBS were applied to antigen-coated wells for $1 \mathrm{~h}$ at RT. Levels of IgGs were determined using biotin-conjugated antibodies against IgG (Sigma-Aldrich, Germany), IgG1 (MP Biomedicals, USA), or IgG2a (Southern Biotech, USA). The amount of antibody was expressed in arbitrary ELISA units calculated from anti-OVA titer: 1 Unit $=1 / 100$ titers of antibodies specific to OVA.

\section{Statistical analysis}

Statistical significance between two groups were tested using Student's $t$ test. For more groups, comparison oneway ANOVA and Tukey post hoc tests were used. Results are expressed as a mean \pm SEM values. A $p$ value $<0.05$ was considered statistically significant. Analysis was performed using GraphPad Prism ver. 5.01 program (GraphPad Software, USA).

\section{Results}

\section{Influence of $\mathrm{EPS}_{37}$ on the production of ROS by neutrophils}

To answer the question whether exopolysaccharides released from bacteria may affect ROS production by inflammatory cells, non-stimulated and zymosan-stimulated neutrophils were incubated with EPS $_{37}$. The effect was compared with that of LTA and LPS (Fig. 1). In order to determine the effect of tested substances on an intracellular and extracellular level of ROS, luminol-dependent (Fig. 1A) or lucigenine-dependent (Fig. 1B) chemiluminescence was measured, respectively. The cells generated and secreted significant amounts of ROS in response to zymosan. In contrast, $\mathrm{EPS}_{37}$, LTA and LPS did not induce ROS production when added alone to non-stimulated neutrophils. Interestingly, $\mathrm{EPS}_{37}$ and LTA added to neutrophils before stimulation with zymosan inhibited formation of ROS by about $40 \%$. The effect was observed only in the case of luminol-dependent chemiluminescence (Fig. 1A). What is more, incubation of $\mathrm{EPS}_{37}$ with $\mathrm{HOCl}$ resulted in scavenging of $\mathrm{HOCl}$ as indicated from alteration of the HOCl-specific UV absorption curve (Fig. 1C).

\section{Effect of $\mathrm{EPS}_{37}$ and LTA on release of cytokines from macrophages}

In order to determine immunostimulatory properties of pure $\mathrm{EPS}_{37}$ and LTA, peritoneal macrophages were cultured for $24 \mathrm{~h}$ with selected concentrations of examined factors. The results clearly indicate strong stimulatory properties of LTA. LTA at a concentration of $30 \mu \mathrm{g} / \mathrm{ml}$ and $100 \mu \mathrm{g} / \mathrm{ml}$ LTA significantly induced the production of all tested cytokines (TNF- $\alpha$, IL-6, IL-12p40 and IL-10), while $\mathrm{EPS}_{37}$ had no effect, as it is shown in Fig. 2. 


\section{Effect of $\mathrm{EPS}_{37}$ on phagocytic activity of macrophages}

To answer the question whether $\mathrm{EPS}_{37}$ can affect the phagocytic activity of macrophages, the cells were incubated with $\mathrm{EPS}_{37}$ and then with RITC-Dextran. The effect was compared with that of LPS. As shown in Fig. 3, neither $\mathrm{EPS}_{37}$ nor LPS altered phagocytosis of dextran molecules by macrophages.

\section{Effect of $\mathrm{EPS}_{37}$ on COX-2 expression and $\mathrm{PGE}_{2}$ synthesis by macrophages}

To examine the relative potency of EPS $_{37}$, LTA and LPS in induction of eicosanoids production by macrophages, the cells were cultured with the tested agents. The expression of COX-2 was estimated in the cell cytosol and the level of $\mathrm{PGE}_{2}$ was determined in supernatants, as described in Material and methods. Non-stimulated macrophages neither expressed COX-2 protein nor released $\mathrm{PGE}_{2}$, the major eicosanoid of macrophages, as shown in Fig. 4. LTA and LPS-stimulated macrophages expressed high levels of COX-2 and produced a significant amount of $\mathrm{PGE}_{2}$. In contrast, the pure $\mathrm{EPS}_{37}$ did not induce expression of COX-2 protein and the level of secreted $\mathrm{PGE}_{2}$ was comparable to that observed in non-stimulated macrophages.

\section{Effect of $\mathrm{EPS}_{37}$ and LTA on release of cytokines from dendritic cells}

Dendritic cells were stimulated with selected concentrations of $\mathrm{EPS}_{37}$ to determine whether $\mathrm{EPS}_{37}$ affects cytokines production by antigen presentation cells. The effect was compared with that of LTA and LPS (Fig. 5). LPS was the strongest inducer of all tested cytokines. There was also a massive release of IL-12p40 in response to LTA, while the influence of LTA on IL- 6 and IL-10 production was negligible. In contrast to LPS and LTA, EPS 37 did not stimulate the production of any of the tested cytokines.

\section{Effect of $\mathrm{EPS}_{37}$ on humoral immune response in mice}

Previously we have shown that pure EPS inhibited the in vivo production of total IgG specific to OVA. In the present study we have extended the observation to other IgG isotypes to examine the hypothesis considering polarization of the immune response by bacterial products. The results shown in Fig. 6 clearly indicate that $\mathrm{EPS}_{37}$ is able to inhibit humoral response to OVA in mice. $\mathrm{EPS}_{37}$ injected simultaneously with the antigen decreased markedly the production of anti-OVA IgG (65\% of inhibition), IgG1 $(90 \%)$ and $\mathrm{IgG} 2 \mathrm{a}(82 \%)$ antibodies. Interestingly, $\mathrm{EPS}_{37}$ given together with LPS diminished its adjuvant properties by inhibiting OVA-specific IgG production, especially antiOVA IgG2a (87\%) (Fig. 6C).

\section{Discussion}

Lactobacilli represent bacteria of human microbiome and are most commonly used for probiotic therapy [16, 17].

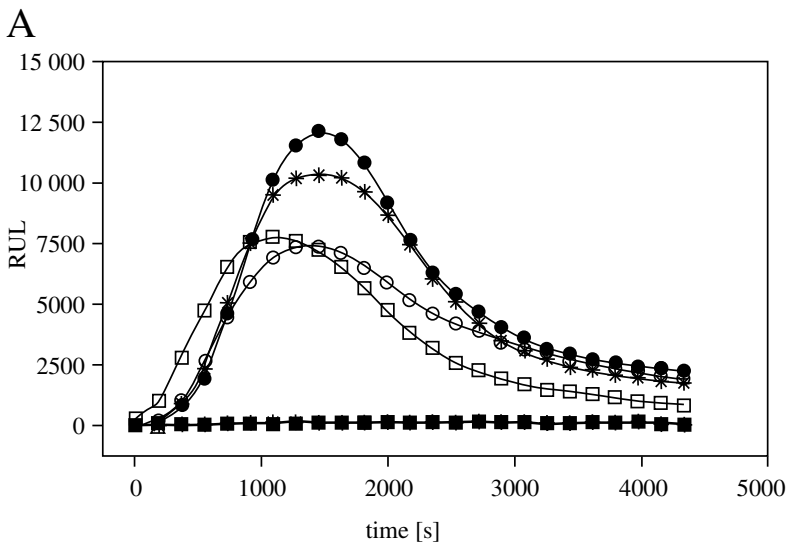

B

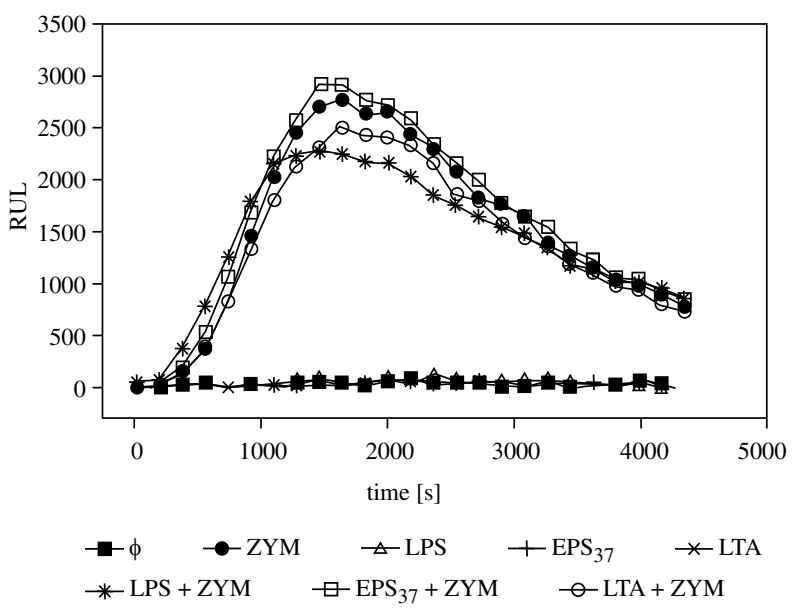

C

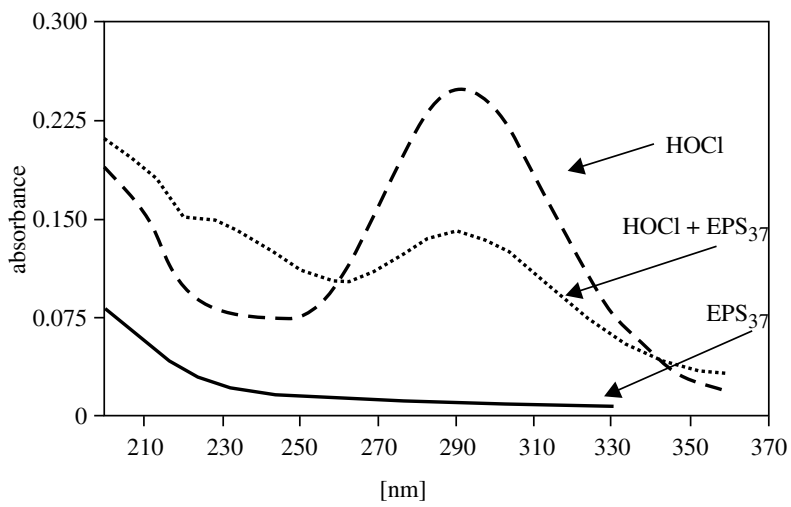

Fig. 1. The effect of $\mathrm{EPS}_{37}$ on production of ROS by neutrophils. LPS $(0.1 \mu \mathrm{g} / \mathrm{ml})$ or $\operatorname{EPS}_{37}(100 \mu \mathrm{g} / \mathrm{ml})$ or LTA $(100 \mu \mathrm{g} / \mathrm{ml})$ was added to either non-stimulated or zymosan-stimulated neutrophils (ZYM, $0.2 \mathrm{mg} / \mathrm{ml}$ ). The level of ROS was measured by chemiluminescence dependent either on luminol (A) or lucigenine (B), as described in Methods. The experiment was repeated three times, the graph shows one representative experiment. RLU - relative light units. (C) The UV absorption spectra of $\mathrm{HOCl}$ after incubation with $\mathrm{EPS}_{37}$ 
A

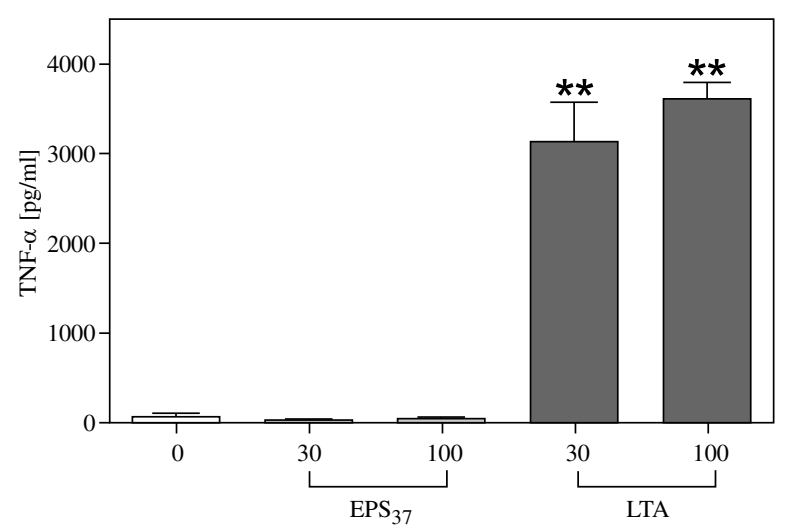

$\mathrm{C}$

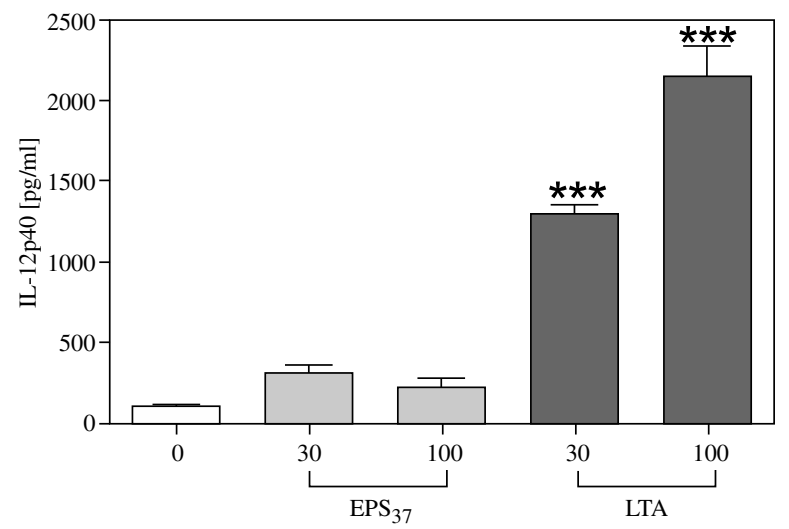

$\mathrm{B}$

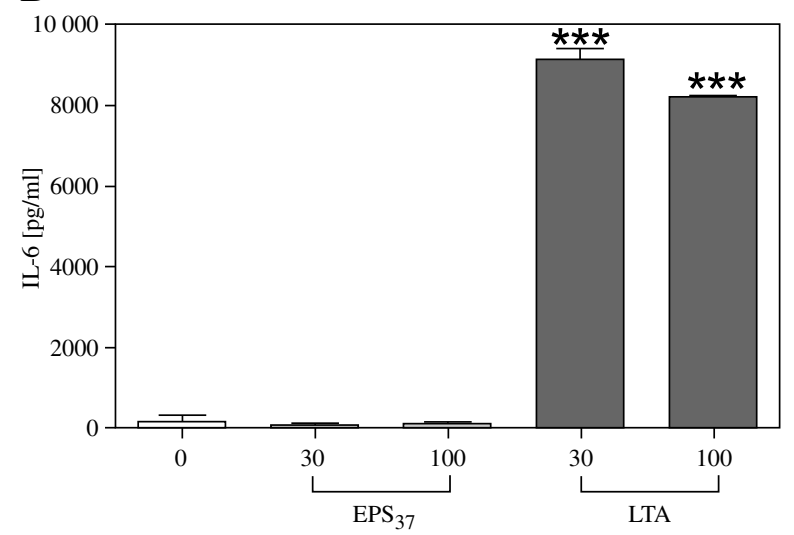

D

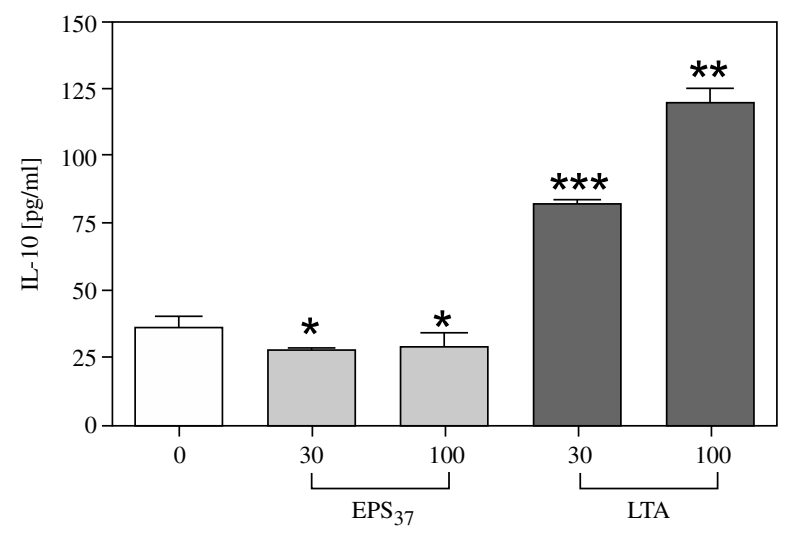

Fig. 2. The effect of $\mathrm{EPS}_{37}$ and LTA on cytokine secretion by macrophages. Peritoneal macrophages $\left(5 \times 10^{5} / \mathrm{ml}\right)$ were incubated with EPS $_{37}$ or LTA (30 and $100 \mu \mathrm{g} / \mathrm{ml}$ ). The levels of TNF- $\alpha$ (A), IL-6 (B), IL-12p40 (C) and IL-10 (D) were measured in cultures supernatants after $24 \mathrm{~h}$ of incubation by the ELISA test. Results are expressed as a mean of three independent experiments \pm SEM. $* p<0.05, * * p<0.01, * * * p<0.001$ non-stimulated cells versus stimulated cells

Our previous study indicates that immunoregulatory properties of lactobacilli are strain specific [18]. In addition, other authors have shown that this effect may be achieved using bacterial components such as LTA or peptidoglycan [19, 20]. Much less is known about the immunoregulatory effect of EPS. However, we have previously shown that crude EPS from Lactobacillus rhamnosus KL37C exerts an immunostimulatory effect on mouse macrophages in vitro [12]. It is of great interest to explain a contribution of EPS in bacteria - immune system cross-talk, especially in bacteria which synthesize EPS as a major component of biofilm matrix [21].

In this study we have investigated the effect of pure EPS $_{37}$ on the selected functions of major cells of acute inflammation, namely: neutrophils, macrophages and dendritic cells. We have found that EPS $_{37}$, and LTA significantly decrease the level of ROS in mouse neutrophils stimulated by zymosan. This can indicate an antioxidant capacity of pure EPS $_{37}$ similar to that of LTA. Antioxidant properties of EPS have been also described by Kodali et al. They have demonstrated that EPS from Bacillus coagulans RK-02 has antioxidant properties and may act as a scavenger of free radicals. These properties were comparable with those of standard antioxidants such as vitamin C and E [22]. Further, we investigated the influence of $\mathrm{EPS}_{37}$ on the phagocytic function of macrophages. The ability of cells to phagocyte dextran molecules in the presence of pure $\mathrm{EPS}_{37}$ was not inhibited. In addition, pure $\mathrm{EPS}_{37}$, in contrast to the crude form described before [12], did not stimulate murine peritoneal macrophages to produce cytokines. Furthermore, there was no effect of $\mathrm{EPS}_{37}$ on $\mathrm{PGE}_{2}$ synthesis and $\mathrm{COX}-2$ protein expression in macrophages. This suggests that pure $\mathrm{EPS}_{37}$ is not a key component of Lactobacillus rhamnosus responsible for its immunostimulating properties. Therefore, we compared the effect of $\mathrm{EPS}_{37}$ with LTA isolated from the same bacteria. LTA showed a strong stimulatory effect. Macrophages stimulated with high concentrations of LTA produced a significant level of both pro-and anti-inflammatory cytokines. LTA also stimulated macro- 

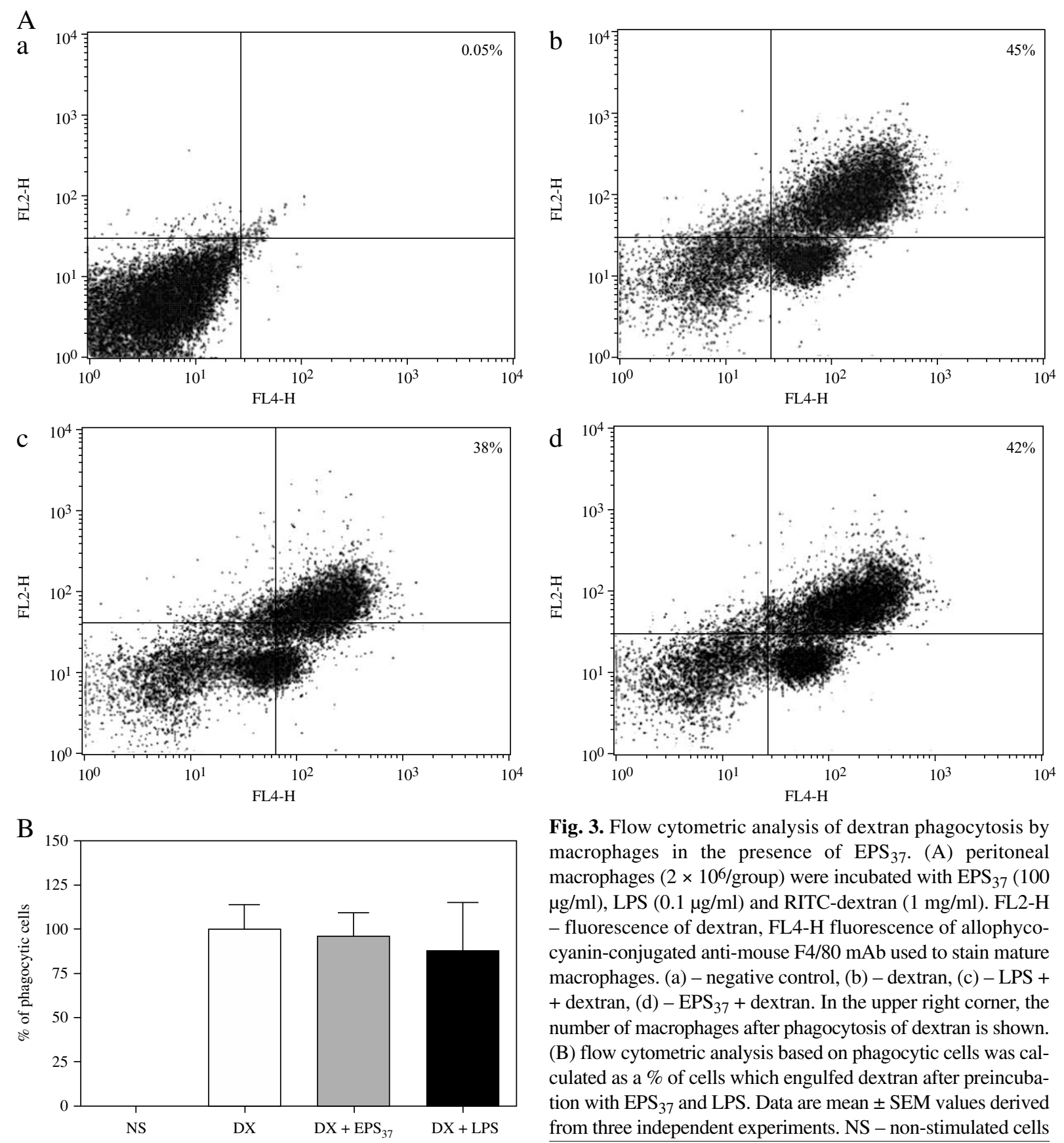

Fig. 3. Flow cytometric analysis of dextran phagocytosis by macrophages in the presence of $\mathrm{EPS}_{37}$. (A) peritoneal macrophages $\left(2 \times 10^{6} /\right.$ group $)$ were incubated with $\operatorname{EPS}_{37}(100$ $\mu \mathrm{g} / \mathrm{ml})$, LPS $(0.1 \mu \mathrm{g} / \mathrm{ml})$ and RITC-dextran $(1 \mathrm{mg} / \mathrm{ml})$. FL2-H - fluorescence of dextran, FL4-H fluorescence of allophycocyanin-conjugated anti-mouse $\mathrm{F} 4 / 80 \mathrm{mAb}$ used to stain mature macrophages. (a) - negative control, (b) - dextran, (c) - LPS + + dextran, (d) $-\mathrm{EPS}_{37}+$ dextran. In the upper right corner, the number of macrophages after phagocytosis of dextran is shown. (B) flow cytometric analysis based on phagocytic cells was calculated as a $\%$ of cells which engulfed dextran after preincubation with $\mathrm{EPS}_{37}$ and LPS. Data are mean \pm SEM values derived from three independent experiments. NS - non-stimulated cells

phages to synthesize $\mathrm{PGE}_{2}$ and $\mathrm{COX}-2$ protein. These data are consistent with other studies where LTA, derived from Gram (+) bacteria, exerts also immunostimulatory effects [23-25]. LTA can strongly induce synthesis of $\mathrm{PGE}_{2}$ and COX-2 not only in immune cells. For example, $\mathrm{PGE}_{2}$ secretion was observed in human lung epithelial cells and neurons of the cerebral cortex in rats after stimulation with LTA $[26,27]$. As immunostimulatory effects depend on both, bacterial cell-wall components and on target cells, we have also examined effects of LTA and EPS $_{37}$ on cytokine pro-

duction by dendritic cells. We have observed a significant production of IL-12p40 and small amounts of IL-6 in 24hour DC cultures stimulated with tested agents. There are very few data showing effects of probiotic bacteria components on DC functions and they mainly concern whole bacteria. Weiss et al. have shown that probiotic bacteria can interact with DC in two ways. Such strains as Lactobacillus acidophilus, Lactobacillus gasseri, Lactobacillus casei and Lactobacillus plantarum induced murine myeloid DC to synthesize IL-12 and TNF- $\alpha$. They observed the oppo- 
A

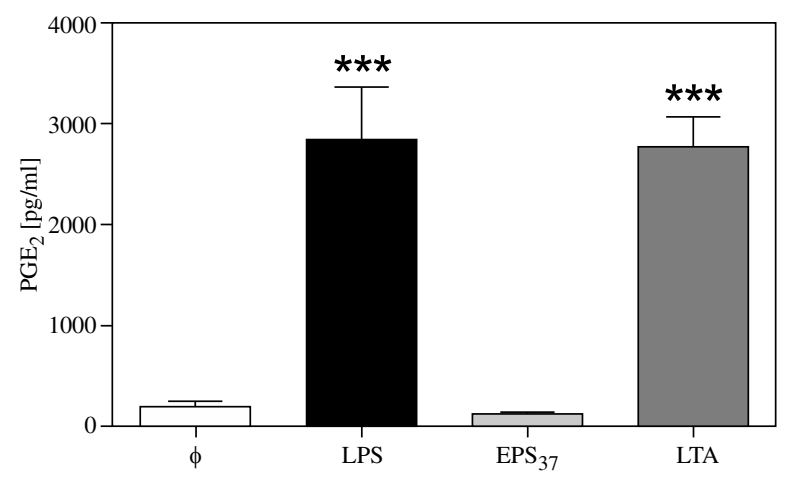

B
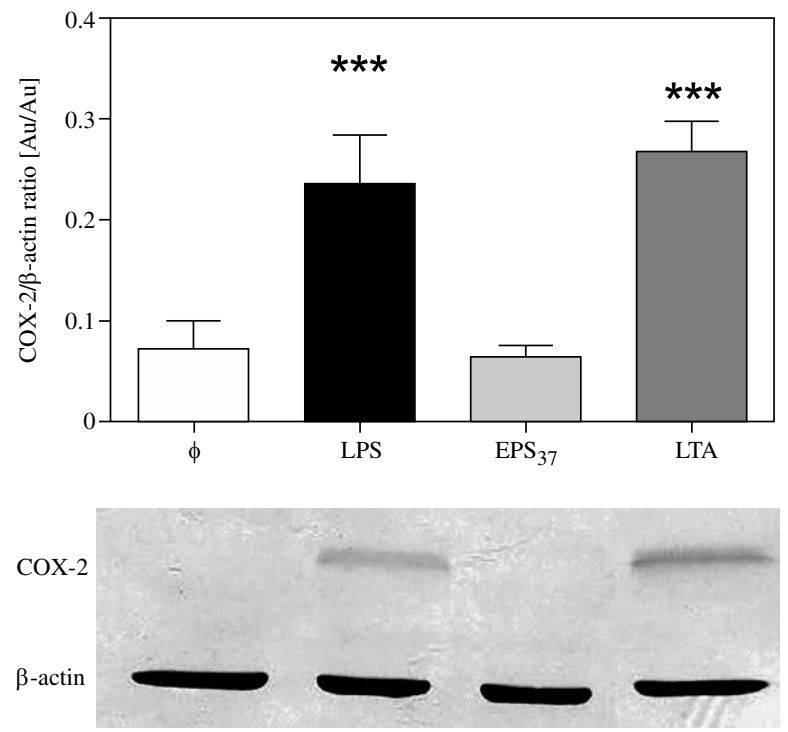

Fig. 4. The effect of $\mathrm{EPS}_{37}$ on production of $\mathrm{PGE}_{2}$ and expression of COX-2 in macrophages. Cells $\left(5 \times 10^{5} / \mathrm{ml}\right)$ were cultured in the presence of LPS $(0.1 \mu \mathrm{g} / \mathrm{ml}), \operatorname{EPS}_{37}(100 \mu \mathrm{g} / \mathrm{ml})$ and LTA $(100 \mu \mathrm{g} / \mathrm{ml})$. After $24 \mathrm{~h}$ of stimulation PGE $_{2}$ level (A) in culture supernatants and COX-2 level (B) in macrophages were determined as described in Material and methods. Results are expressed as a mean of three independent experiments \pm SEM. $* p<0.05, * * * p<0.001$ non-stimulated cells versus stimulated cells. NS - non-stimulated cells. Picture shows one selected, representative Western blot analysis

site effect in the case of use of Bifidobacterium bacteria [28]. Evrard et al. showed that L. rhamnosus Lcr35 increased synthesis of the Th1/Th17 cytokine profile, but had no significant effect on the level of IL-10 [29]. Previously, we have demonstrated the impact of $\mathrm{EPS}_{37}$ on humoral immune response in mice. We have shown that EPS $_{37}$ inhibited synthesis of IgG specific to OVA. The effect of EPS was opposite to the effect of LPS. LPS was a strong adjuvant and significantly enhanced OVA-specific response [30]. In this study, we expand our investigations to other
A

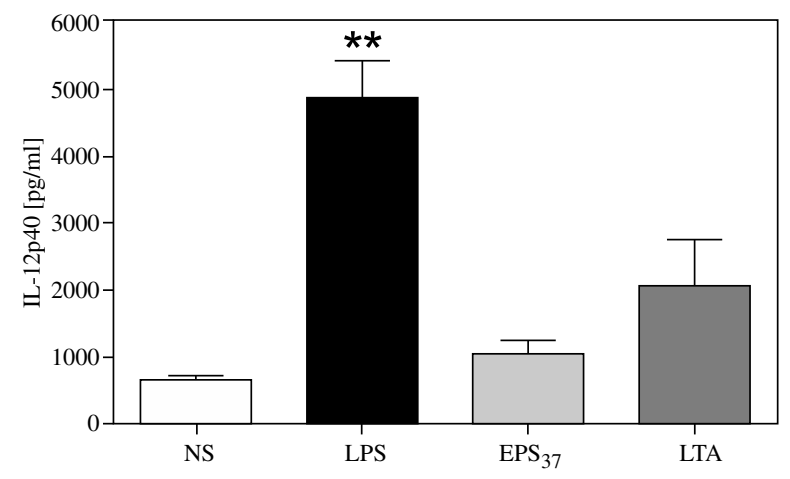

B

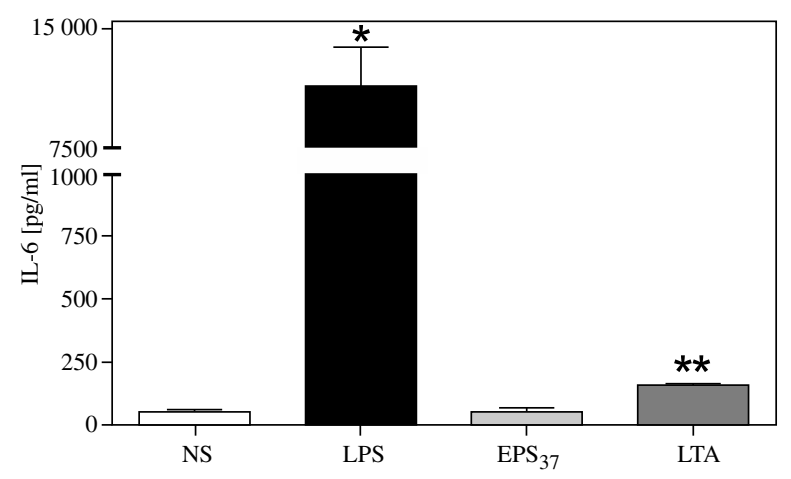

$\mathrm{C}$

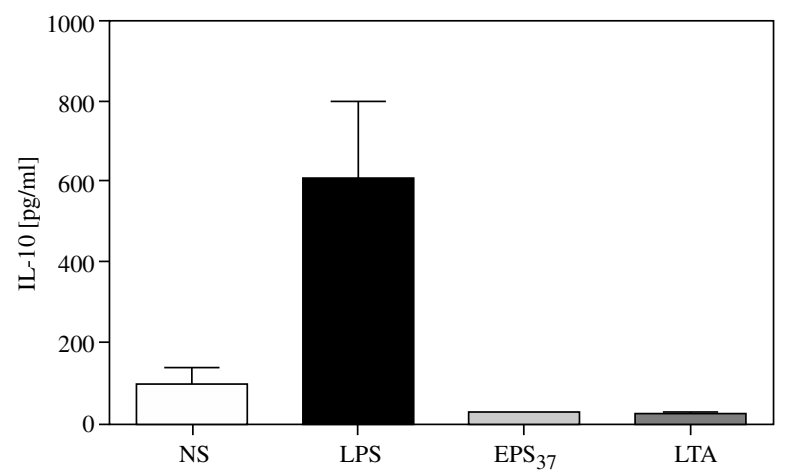

Fig. 5. The effect of $\mathrm{EPS}_{37}$ on cytokine production by DC. Cells $\left(6 \times 10^{4} / \mathrm{ml}\right)$ were cultured in the presence of LPS $(0.1$ $\mu \mathrm{g} / \mathrm{ml}), \operatorname{EPS}_{37}(100 \mu \mathrm{g} / \mathrm{ml})$ and LTA $(100 \mu \mathrm{g} / \mathrm{ml})$. The concentrations of IL-12p40 (A), IL-6 (B) and IL-10 (C) were measured by ELISA in culture supernatants after $24 \mathrm{~h}$ of incubation. NS - non-stimulated cells. Results are expressed as a mean of three independent experiments \pm SEM. $* p<0.05$, $* * p<0.01$ non-stimulated cells versus stimulated cells

OVA-specific IgG isotypes to examine the hypothesis considering polarization of the immune response by the bacterial product. We have found that $\mathrm{EPS}_{37}$ diminished the serum level of OVA-specific IgG1 and IgG2a antibodies to the same degree. Moreover, EPS $_{37}$ also inhibited the adju- 
A

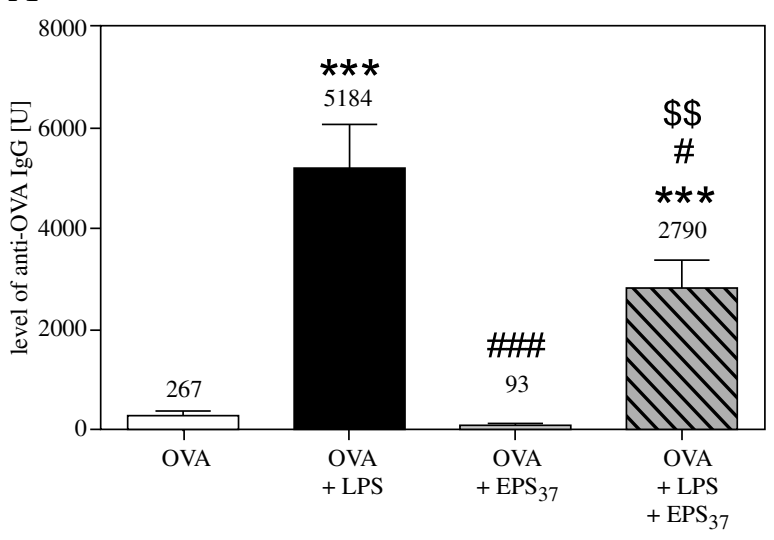

B

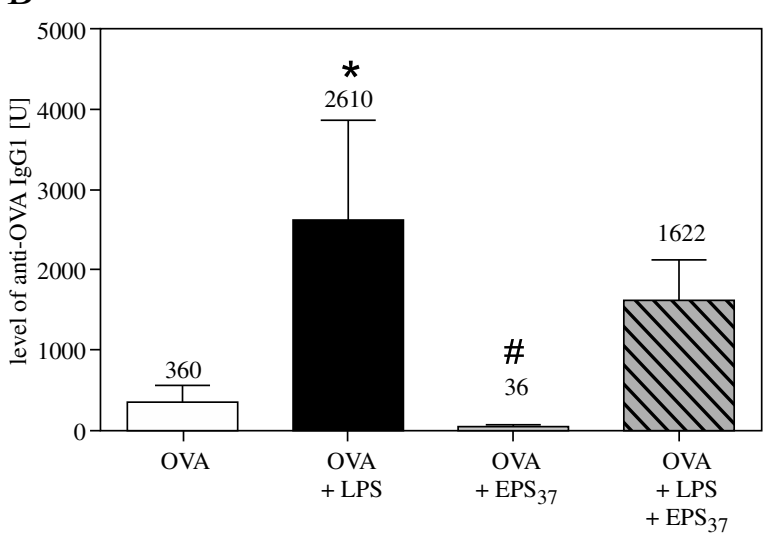

C

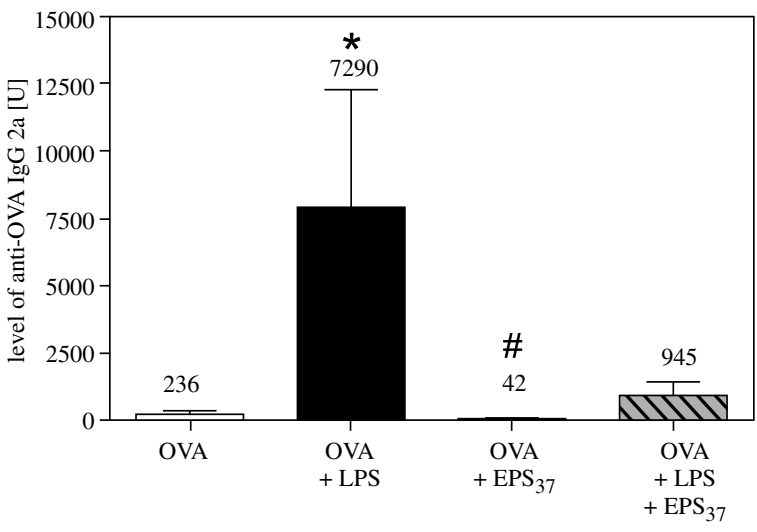

Fig. 6. The effect of $\mathrm{EPS}_{37}$ on OVA-specific humoral response. Mice were immunized intraperitoneally with $200 \mu \mathrm{g}$ OVA together with LPS $(1 \mu \mathrm{g} /$ mouse $)$ or $\operatorname{EPS}_{37}(50 \mu \mathrm{g} / \mathrm{mouse})$ on days 0 and 14. The levels of $\operatorname{IgG}(\mathrm{A}), \operatorname{IgG1}(\mathrm{B})$ and $\operatorname{IgG} 2 \mathrm{a}(\mathrm{C})$ specific to OVA were measured by ELISA 7 days after the second immunization. The results are expressed in arbitrary units: $1 \mathrm{U}=1 / 100$ titers of $\mathrm{IgG}$ anti-OVA $\pm \operatorname{SEM}(n=10)$. Results are a mean of two independent experiments. $* p<0.05$ vs. OVA; $* * * p<0.001$ vs. OVA; $\# p<0.05$ vs. LPS; \#\#\# $<0.001$ vs. LPS, $\$ \$ p<0.01$ vs. EPS $_{37}$. The levels of IgGs are shown in numbers vant effect of LPS in the same way. Therefore, our present results did not show polarizing properties of $\mathrm{EPS}_{37}$, while confirmed its suppressor effect on antigen-specific humoral response in mice.

In conclusion, the present study extends our knowledge concerning biological properties of bacterial EPSs. However, some fundamental questions are still unanswered. We can suggest that pure EPS, at least EPS from L. rhamnosus KL37C, shows a very weak, immunostimulatory action if compared with that of LTA (major component of lactobacilli cell wall). One may suggest that it is the effect of lack of EPS-specific PRR receptor (not yet found). On the other hand, EPS is the main component of biofilm matrix. It may suggest its protecting role against immune attack on bacteria hidden in biofilm. However, further studies are necessary to investigate the role of EPS in the interaction between bacteria and the immune system cells. Proper understanding of these interactions may open new strategies for probiotic therapies. Importantly, due to a large heterogeneity of bacterial EPSs, biological properties of each individual bacterial strain must be taken into account. Indeed, we have shown that potential of EPS is strain-dependent. EPSs isolated from three different strains of Lactobacillus (L. reuteri, $L$. johnsonii and $L$. animalis/murinus) stimulated the murine macrophage to produce both pro- and anti-inflammatory cytokines in a different manner [31].

The authors declare no conflict of interests.

This study was support by the Ministry of Science and Higher Education (Poland) grants No. NN401 048838 and No. NN401 042438.

\section{References}

1. Sengül N, Işık S, Aslım B, et al. (2011): The effect of exopolysaccharide-producing probiotic strains on gut oxidative damage in experimental colitis. Dig Dis Sci 56: 707-714.

2. Ruas-Madiedo P, Gueimonde M, Margolles A (2006): Exopolysaccharides produced by probiotic strains modify the adhesion of probiotics and enteropathogens to human intestinal mucus. Food Prot 69: 2011-2015.

3. Ruas-Madiedo P, de los Reyes-Gavilán CG (2005): Invited review: methods for the screening, isolation, and characterization of exopolysaccharides produced by lactic acid bacteria. J Dairy Sci 88: 843-856.

4. Säwén E, Huttunen E, Zhang X, et al. (2010): Structural analysis of the exopolysaccharide produced by Streptococcus thermophilus ST1 solely by NMR spectroscopy. J Biomol NMR 72: 125-134.

5. Makino S, Ikegami S, Kano H, et al. (2006): Immunomodulatory effects of polysaccharides produced by Lactobacillus delbrueckii ssp. bulgaricus OLL1073R-1. J Diary Sci 89: 2873-2881.

6. Salazar N, Ruas-Madiedo P, Kolida S, et al. (2009): Exopolysaccharides produced by Bifidobacterium longum IPLA E44 and Bifidobacterium animalis subsp. lactis IPLA R1 modify the composition and metabolic activity of human 
faecal microbiota in pH-controlled batch cultures. Int J Food Microbiol 135: 260-267.

7. Ciszek-Lenda M (2011): Biological functions of exopolysaccharides from probiotic bacteria. Centr Eur J Immunol 36: 51-55.

8. Badel S, Bernardi T, Michaud P (2011): New perspectives for lactobacilli exopolysaccharides. Biotechnol Adv 29: 54-66.

9. Burns P, Reinheimer J, Vinderola G (2011): Impact of bile salt adaptation of Lactobacillus delbrueckii subsp. lactis 200 on its interaction capacity with the gut. Res Microbiol 162: 782-790.

10. Forde A, Fitzgerald GF (1999): Bacteriophage defence systems in lactic acid bacteria. Antonie Van Leeuwenhoek 76: 89-113.

11. Péant B, LaPointe G, Gilbert C, et al. (2005): Comparative analysis of the exopolysaccharide biosynthesis gene clusters from four strains of Lactobacillus rhamnosus. Microbiology 151: 1839-1851.

12. Ciszek-Lenda M, Nowak B, Śróttek M, et al. (2011): Immunoregulatory potential of exopolysaccharide from $\mathrm{Lac}$ tobacillus rhamnosus KL37. Effects on the production of inflammatory mediators by mouse macrophages Int J Exp Pathol 92: 382-391.

13. Nowak B, Ciszek-Lenda M, Sróttek M, et al. (2012): Lactobacillus rhamnosus exopolysaccharide ameliorates arthritis induced by the systemic injection of collagen and lipopolysaccharide in DBA/1 mice. Arch Immunol Ther Exp 60: 211-220.

14. Górska-Frączek S, Sandström C, Kenne L, et al. (2011): Structural studies of the exopolysaccharide consisting of a nonasaccharide repeating unit isolated from Lactobacillus rhamnosus KL37B. Carbohydr Res 27: 2926-2932.

15. Laemmli UK (1970): Cleavage of structural proteins during the assembly of the head of bacteriophage T4 Nature 227: 680-685.

16. Meijer BJ, Dieleman LA (2011): Probiotics in the treatment of human inflammatory bowel diseases: update 2011. J Clin Gastroenterol 45: 139-144.

17. Koren O, Knights D, Gonzalez A (2013): A guide to enterotypes across the human body: meta-analysis of microbial community structures in human microbiome datasets. PLoS Comput Biol 9: e1002863.

18. Marcinkiewicz J, Ciszek M, Bobek M, et al. (2007): Differential inflammatory mediator response in vitro from murine macrophages to lactobacilli and pathogenic intestinal bacteria. Int J Exp Pathol 88: 155-164.

19. Matsuguchi T, Takagi A, Matsuzaki T, et al. (2003): Lipoteichoic acids from Lactobacillus strains elicit strong tumor necrosis factor alpha-inducing activities in macrophages through Toll-like receptor 2. Clin Diagn Lab Immunol 10: 259-266.

20. Sun J, Shi Y-H, Le G-W, et al. (2005): Distinct immune response induced by peptidoglycan derived from Lactobacillus sp. World J Gastroenterol 11: 6330-6337.

21. Vu B, Chen M, Crawford RJ, et al. (2009): Bacterial extracellular polysaccharides involved in biofilm formation. Molecules 14: 2535-2554.

22. Kodali VP, Sen R (2008): Antioxidant and free radical scavenging activities of an exopolysaccharide from a probiotic bacterium. Biotechnol J 3: 245-251.

23. Ginsburg I (2002): Role of lipoteichoic acid in infection and inflammation. Lancet Infect Dis 2: 171-179.

24. Su SC, Hua KF, Lee H (2006): LTA and LPS mediated activation of protein kinases in the regulation of inflammatory cytokines expression in macrophages. Clin Chim Acta 374: 106-115.
25. Chang YC, Li PC, Chen BC, et al. (2006): Lipoteichoic acidinduced nitric oxide synthase expression in RAW 264.7 macrophages is mediated by cyclooxygenase-2, prostaglandin E2, protein kinase A, p38 MAPK, and nuclear factor-kappaB pathways. Cell Signal 18: 1235-1243.

26. Lin CH, Kuan IH, Lee HM, et al. (2001): Induction of cyclooxygenase- 2 protein by lipoteichoic acid from Staphylococcus aureus in human pulmonary epithelial cells: involvement of a nuclear factor-kappa B-dependent pathway. $\mathrm{Br}$ J Pharmacol 134: 543-552.

27. Wu HH, Hsieh WS, Yang YY, Tsai MC (2006): Lipoteichoic acid induces prostaglandin $\mathrm{E}(2)$ release and cyclooxygenase2 synthesis in rat cortical neuronal cells: involvement of PKC epsilon and ERK activation. Life Sci 79: 272-280.

28. Weiss G, Christensen HR, Zeuthen LH, et al. (2011): Lactobacilli and bifidobacteria induce differential interferon- $\beta$ profiles in dendritic cells. Cytokine 56: 520-530.

29. Evrard B, Coudeyras S, Dosgilbert A (2011): Dose-dependent immunomodulation of human dendritic cells by the probiotic Lactobacillus rhamnosus Lcr35. PLoS One 6: e18735.

30. Ciszek-Lenda M, Nowak B, Śróttek M, et al. (2012): Immunosuppressive effect of systemic administration of Lactobacillus rhamnosus KL37C-derived exopolysaccharide on the OVAspecific humoral response. Centr Eur J Immunol 37: 338-344.

31. Ciszek-Lenda M, Strus M, Górska-Frączek S, et al. (2011): Strain specific immunostimulatory potential of lactobacilliderived exopolysaccharides. Centr Eur J Immunol 36: 121-129. 